\title{
Homework: At Home or at School?_-Attitudes of Teachers, Parents and the General Public: A Case Study
}

\author{
Roman Yavich ${ }^{1} \&$ Nitza Davidovitch ${ }^{2}$ \\ ${ }^{1}$ Department of Mathematics, Ariel University, Ariel, Israel \\ ${ }^{2}$ School of Education, Ariel University, Ariel, Israel \\ Correspondence: Roman Yavich, Department of Mathematics, Ariel University, Ariel, Israel. E-mail: \\ romany@ariel.ac.il
}

Received: January 15, 2020

Accepted: February 18, 2020

Online Published: May 29, 2020

doi:10.5539/ies.v13n6p170

URL: https://doi.org/10.5539/ies.v13n6p170

\begin{abstract}
The purpose of this study is to investigate the attitudes of three influential groups toward homework: parents, teachers and the public. Specifically, attitudes toward reducing and eliminating homework, as well as creating alternatives to conventional homework, are examined. The first hypothesis is that the attitude of teachers and parents toward homework is positive, whereas that of the public is negative, in line with the Israeli Ministry of Education that suggests changing homework policies. Another hypothesis is that there is a correlation between the seniority of teachers and their attitudes toward homework - the greater the seniority, the more negative the attitude. Finally, the effect of various background variables of teachers (class grade and subject area: sciences or humanities) and parents (age of parents, number of children in the family and child birth-order) on their attitudes toward homework is examined. The first research hypothesis was confirmed-most teachers and parents are supportive of homework, whereas the public is the least supportive. In addition, the public is the most supportive of changing homework policies, parents are less supportive, and teachers are the least supportive. No correlation was found between the seniority of teachers and their attitudes toward homework. Finally, background variables have no effect on attitudes toward homework. According to these findings, the public is not yet ready to completely forgo homework, which has been so widely used and accepted. The desire to change the traditional homework policy exists, but the concept that homework is essential remains.
\end{abstract}

Keywords: homework, parents, teachers, university students

\section{Introduction}

For many years, teachers and parents worldwide have viewed homework as an integral part of the learning process (Cooper, 1989). Despite this, homework has not been researched enough, and even in the existing literature there are many disagreements regarding the efficacy of homework and its effect on learning. Existing studies focus on the characteristics of homework, how these characteristics interact between themselves and how they affect student achievement, study habits and student responsibility (Buzukashvily, 2009). Homework is widely debated and discussed in the press, by the government, in government ministries and by various socially influential pressure groups. Almost every decade, the debate about homework surfaces and it is affected by changing opinions and points of view on childhood and leisure time. Moreover, it is affected by changes in attitude toward the curriculum, teaching methods and school quality (Katipoglu, 1993).

There is a large amount of evidence that attitude plays an important role in shaping and determining behavior (Kraus, 1995). Attitudes toward homework, however, are inconsistent. Over the last century, the public attitude toward homework has changed from positive to negative and back. Homework is noticeably a source of friction between teachers and students, children and parents, and teachers and parents. Many pediatricians and family doctors point out that problems with homework are a common source of concern reported by children with medical problems. Therefore, it is important to determine whether the attitudes of parents, teachers and students toward homework are consistent (Cooper et al., 1998). There is little reference in the literature to the attitudes of parents and teachers toward homework (Katipoglu, 1993). The general tendency of researchers is primarily to correlate the preparation of homework with school achievements. Based on the results, some conclude that homework should not be assigned, while others conclude it should (Cooper et al., 1998). Both teachers and parents were generally found to hold positive attitudes toward homework (Katipoglu, 1993). Despite this, 
teachers mention many factors that negatively affect homework, such as a shortage of required resources in the homes of students (Haffila et al., 2018). Moreover, a study on the attitudes of elementary-school teachers, parents and students toward homework found that teachers hold contradicting attitudes, not only positive attitudes as mentioned in the literature (Xu \& Yuan, 2003). Some teachers view homework as a way to review, teach and correct class material and, in their opinion, it is a fundamental part of the learning process. Conversely, other teachers believe that there are more innovative ways to learn and review class material. Most parents hold a positive attitude toward homework and believe that it is an important part of the learning process but, in practice, it is evident that some parents do not invest time in helping and encouraging their children to prepare their homework (Davidovitch \& Yavich, 2017).

\subsection{What Is Homework?}

Homework is defined as "tasks that teachers assign to students at school, which the students are required to complete after school hours, and which are considered a common learning strategy". The homework procedure is complex and requires the participation of three main parties: parents, teachers and students. Each of them has objectives and behaviors that may come into conflict with the others (Rosário et al., 2015). Homework preparation involves complicated interactions between a greater number of factors than any other teaching tool. Because homework is meant to be completed at home, many factors may affect its quality, such as student abilities, motivation, study habits, classroom level, the amount of homework and its goal, the lighting at the students' homes, the level of noise and the availability of a space with no distractions (Cooper, 1989). However, when it was decided to prolong the school day, homework was officially incorporated into the school curriculum. Therefore, homework is not necessarily prepared at home (Rawson et al., 2017). Homework can be defined as learning activities and tasks that are meant to be performed after the formal school lessons, and which can be performed within the school area (the school library or classroom); but even using this expanded definition, the students are required to complete any unfinished tasks at home (Davidovitch \& Yavich, 2017).

\subsection{The Aims of Homework}

The Israeli Ministry of Education and Culture (regulations for elementary schools) requires homework as a matter of principle and lists three main aims (Fleischer \& Ohel, 1977):

1) To provide reinforcement of classroom lessons.

2) To provide preparation for subsequent lessons.

3) To promote independent thinking and learning and the acquisition of good study habits.

Accordingly, researchers offer a definition of homework that includes three basic categories: practice \& drill, preparation and further study. Some distinguish between drill and review_drill refers to repetitive exercises that are practiced until the material is mastered (for example, math exercises), whereas review refers to mastering the material by reading and memorization. The purpose of preparation-type homework is to provide background knowledge that may enhance classroom learning. Homework for further study adds extra knowledge and learning experience beyond what is learned at school, and its purpose is to promote the development of independent thinking, imagination and creativity (Shemer, 1995). Moreover, assigning homework for students to prepare at home offers parents a chance to be involved in the learning process and to improve their appreciation for education. In this regard, homework can potentially be used to develop a collaborative relationship between the school and the home environment of the students (Tam \& Chan, 2009).

Therefore, the rationale behind homework includes three general aims: the first and primary aim is to improve student achievements by practice and drill. The tendency of teachers is to focus on this aim. The second aim of homework is to enhance the motivation and self-regulation of students, thereby providing them with important life abilities such as personal responsibility. The third aim is to strengthen the relationship between the school and the home environment of the students. Since homework allows parents to be informed about the material studied in the classroom, it promotes communication between the parents and school staff (Trautwein et al., 2009).

\subsection{Previous Studies on Homework}

Homework preparation has negative and positive effects on students. Therefore, research does not have much influence on the creation of consistent homework policies. Many policymakers and the general public mention studies that support their position, as well as studies that do not support it (Cooper \& Valentine, 2001). In a meta-analysis study, Cooper (1989) summarizes the various types of effects caused by homework. The positive effects of homework include improved learning skills, the development of personal responsibility, improved memory, the acquirement of new knowledge and the development of critical thinking. Negative influences 
include loss of student interest in the study material, excess parental intervention, a wider achievement gap between students, cheating (copying and private assistance), and physical and emotional fatigue. It was also found that high-school and middle-school students benefit the most from homework, while in elementary schools the effect of homework on student achievement is the most limited. Therefore, attitudes toward homework may vary more in elementary schools (Davidovitch \& Yavich, 2017), where its effectiveness is questionable (Cooper, 1989).

Many studies on homework discuss its advantages and disadvantages. Some researchers claim that homework provides students with immediate benefits such as improved grades, improved classroom performance and a more positive attitude toward learning. Moreover, students enjoy long-term benefits such as the acquirement of time-management and problem-solving skills, which are essential not only for preparing homework but for other purposes throughout life. According to other studies, homework provides additional practice and drill, and creates extra time in which students are involved in learning beyond school time. It broadens the horizons of students and prepares them for handling complex problems (Davidovitch et al., 2016). According to the self-determination and social-cognitive theories, the very fact that homework is the sole responsibility of students increases their motivation and efforts to complete the tasks assigned, out of a sense of commitment and responsibility (Trautwein et al., 2009).

Fleischer and Ohel (1977) summarize the main flaws and risks of homework in Israel based on surveys, studies and conversations with teachers, parents and students. First, they argue, homework sabotages parent-child relationships, because many parents consider it their central role to supervise their children's homework. Second, not all parents are equipped to help their children; even very educated parents do not always possess the knowledge included in the school material or are familiar with the new teaching methods, so that their help is of no use and may even be misleading. This leads to the acquisition of negative learning habits, contrary to the goal of homework. Third, children have difficulty concentrating and are physically and emotionally exhausted when they arrive at home after school, which undermines the effectiveness of homework. Fourth, homework may widen the achievement gap between students, because many homes lack the basic conditions needed for homework preparation (such as a personal computer). Fifth, homework may create hostile teacher-student relationships when it is used as a tool for punishment or when "too much" homework is assigned beyond the capability of the students (Cooper et al., 2012). Teachers tend to be strict and investigative about which students completed their homework and which did not. This sometimes causes students who did not prepare their homework to avoid school and, in some cases, even to develop physical symptoms such as nausea and stomach aches as a result of nervousness and anxiety (Fleischer \& Ohel, 1977).

\subsection{Past Attitudes Toward Homework}

At the beginning of the 20th century, homework was believed to be essential for improving and shaping the minds of students. The brain was perceived as a muscle, and memorization as a mental activity that improves it, not just as a way of acquiring new knowledge. Because memorization is an activity that can easily be performed at home, homework was a key strategy in education. By 1940, people began objecting to homework. The central goal of educators was to change the learning method that was common at the time: instead of learning by practice and drill, learning by developing the ability to problem-solve. The use of homework as a tool for punishment or for the improvement of memorization skills was questioned; instead, developing student proactivity and interest in learning was emphasized. In addition, homework was perceived as an interfering factor during the students' leisure time.

Toward the end of the 1950s, when the Soviet Union launched the Sputnik satellite, the trend toward reducing homework was reversed. Americans became concerned that the education system might not be ensuring that students are prepared for the complex technological future and for confronting ideological adversaries, and homework was perceived as a tool for accelerating knowledge acquisition. In the middle of the 1960s, the trend was reversed again. Homework was considered a tool that pressurizes students to reach high achievements. Contemporary learning theories questioned on the value of homework, and it was claimed again that an increased amount of homework might negatively affect the mental health of students. By the middle of the 1980s, the trend turned back to supporting homework. The reason for this was the drop in student grades on American achievement tests and a growing concern regarding the ability of America to compete in the world market.

From this historical overview it can be concluded that homework is an important part of students' routine, and most educators believe that it is an important addition to school activities (Henderson, 1996). Moreover, the public attitude toward homework is mainly related to the prevailing social philosophy and international 
economic trends rather than to studies on the efficacy of homework and its effectiveness in improving student achievements (Cooper et al., 1998; Cooper \& Valentine, 2001).

\subsubsection{Factors Affecting Teacher Attitudes}

Teachers' professional stage of development affects their attitudes toward creating changes in teaching methods. It was found that teachers in later stages are unsupportive of change, whereas teachers in early and intermediate stages support change (Maskit, 2006). Various researchers (Burke et al., 1987; Fessler, 1995) have defined the developmental stages of teachers as follows: the beginning stage during which teachers become familiar with the profession and job, the stage of refining professional skills, the stage of growth and enthusiasm, the stage of frustration and disillusionment, the stage of stability, the stage of routine and stagnation and the stage of decline. The professional development of teachers is affected, among other factors, by their age and seniority (Maskit, 2006) and, therefore, these variables may also be correlated with teacher attitudes toward such a fundamental change in teaching methods as eliminating or reducing homework. In addition, a negative correlation was found in previous research between the age and seniority of teachers and their general attitude toward homework: the greater the seniority and age, the more negative the attitude toward homework (Davidovitch \& Yavich, 2017). However, it was found that teacher attitudes vary regarding specific factors that affect homework (Haffila et al., 2018). In the current study as well, teacher attitudes may be found to vary on specific issues.

\subsubsection{Factors Affecting Parental Attitudes}

Several factors affect parental behavior regarding homework preparation, such as parents' sense of ability to help their children prepare homework and their motivation to do so. Various studies show that the attitudes of parents toward issues related to learning affect their behavior and the nature of their involvement in the learning processes of their children, including homework preparation. Therefore, when parents believe that homework is an essential tool, this belief is expressed by supportive behavior, namely, explaining the rationale behind homework to their children (Buzukashvily, 2009).

\subsection{The Situation in Israel}

In 2003, the Dovrat Commission was appointed to examine the state of the Israeli education system and provide recommendations and guidelines for implementing pedagogical structural and organizational changes. The Dovrat Report, with the reform that it recommends, emphasizes the fact that the education system in Israel, as in all other countries, is pressured to commit to implementing change and improving efficiency (Dovrat et al., 2006). In 2006, the Ministry of Education issued a guideline publication recommending that the homework policy in elementary schools be re-examined by discussing questions related to the purpose of homework and its benefits, such as the goals of homework, the problems it causes, the types of tasks assigned, parental involvement in homework preparation, the amount assigned and the frequency. According to the guideline publication, each school is required, at the beginning of each year, to provide a detailed account of the school's homework policy, both on the school website and in a note to the parents (Ministry of Education, 2006).

Currently, it seems that the trending attitude toward homework in Israel is turning negative. The Ministry of Education has decided to prohibit elementary schools from punishing students who do not prepare their homework, and teachers are required to reduce the amount of homework they assign. Instead of assigning homework, the recommendation is to encourage students to read at least 10 minutes a day or to engage in enjoyable activities such as math games, word games or scientific experiments with their parents. In general, the aim of the Ministry of Education is for teachers to find alternatives to homework and, until then, it recommends reducing the amount of homework time according to class level (Eini, 2018). Accordingly, Cooper (1989) offers a model that divides the number of tasks, their purpose and the time needed to complete them according to age, for example: in grades 1-3, three tasks should be assigned per week, and the time required for completing each task should be no more than 15 minutes. The goals of the tasks for this age group should be to reinforce positive attitudes toward learning and develop positive study habits and personality traits. In grades 4-6, four tasks should be assigned per week, and the time required for completing each task should be $15-45$ minutes. The goals of the tasks, among others, should be to develop various learning skills, independent study and research skills.

In the current study, the attitudes of teachers, parents and the general public toward homework are examined. Because the topic of homework is raised every so often and debated among influential parties, it is important to examine the attitudes of the abovementioned groups and whether they agree among themselves or not. In previous studies conducted outside Israel, it was found that both parents and teachers generally view homework as a positive teaching strategy (Katipoglu, 1993). In a study conducted in Israel, it was found that there are differences between the attitudes of teachers and parents toward homework (Davidovitch \& Yavich, 2015, 2017). It may be beneficial to examine whether the viewpoint of the Ministry of Education, which supports reducing the 
amount of homework and finding alternatives, is consistent with the current attitudes of teachers, parents, and public opinion.

\subsection{Research Hypotheses}

We assumed that a negative correlation exists between teacher attitudes toward homework and teacher age and seniority, as well as between teacher age and seniority and teacher attitudes toward completely eliminating or reducing the amount of homework and finding alternatives. We assumed that, in general, teachers hold a positive attitude toward homework. We also assumed that most parents hold a positive attitude toward homework but differ on various issues, especially those concerning practical change. In addition, we hypothesized that the general public holds a negative attitude toward homework, in line with the current prevailing opinion, which represents the opinion held by the Ministry of Education and debated in the media (Cooper \& Valentine, 2001). We tested the correlation between the backgrounds of the subjects and their attitudes (positive or negative). Assuming that homework is a complex learning tool subject to the influence of various public groups, it is important to examine the attitudes toward homework and the existence of differences between the various groups.

\section{Methodology}

\subsection{Sample}

The research population consisted of three groups: teachers, parents and the general public. The sample included 151 subjects: fifty were first- to sixth-grade teachers (15 male and 35 female), sampled from Israeli schools countrywide. The average seniority of the teachers was 14.12 years. Fifty-one subjects were parents of elementary-school students, sampled from populations with various characteristics, such as parents with higher-education degrees, parents with only high-school-level education, middle-class parents, orthodox parents, secular parents, parents with different numbers of children and parents of various ages. Fifty subjects were university students representing the general public, and were sampled from Ariel University, Tel Aviv University, the Hebrew University and Bar-Ilan University. The university students were of various religious backgrounds, ages and study areas, such as engineering, psychology, education and nursing.

\subsection{Research Tools}

\subsubsection{Questionnaire on Attitudes Toward Homework}

We used a questionnaire developed by Cooper and his colleagues (Cooper et al., 1998) on attitudes toward homework. The questionnaire includes six items for which the subjects rank their attitudes, beliefs and emotional reactions toward homework (for example, the item: "I think homework helps to create proper working habits in students"). The reliability of the questionnaire was measured in previous studies and found to be alpha $=0.78$ (Buzukashvily, 2009). In addition, eight statements related specifically to the current research were added, focusing on the attitude of the subjects toward changing the homework policy, either by reducing homework or creating alternatives (for example, the item: "Reducing and eliminating homework is an essential step"). Moreover, the questionnaire examines attitudes toward the reasons for creating a change, and whether or not change is believed to be beneficial (for example, the item: "Homework widens gaps between students"). The responses were scored on a Likert scale along a range of five levels of agreement, where 1 represents strong disagreement and 5 represents strong agreement.

\subsubsection{Personal Background Questionnaires}

The subjects in each group received a personal-background questionnaire according to its characteristics. In the questionnaire sent to the parents, they were asked to score the level of homework help they offer on a scale of $1-5$, where 1 represents no help at all and 5 represents a large degree of help.

\subsection{Procedure}

The questionnaires were sent to the subjects electronically, through Google Forms. Before sending the questionnaires, it was clarified to the participants that the questionnaires are anonymous and no personal information is required. Statistical analysis of the questionnaires was performed using SPSS software. The first research hypothesis, that there are differences between the various groups, was tested by independent $t$-tests. The second research hypothesis, that there is a correlation between teacher attitudes and seniority, was tested by a Pearson-correlation test. The third research hypothesis, that most parents hold a positive attitude toward homework but differ on various issues, was tested by independent t-tests. The fourth research hypothesis, that the attitude of the public (university students) is in line with the Ministry of Education, was tested by independent t-tests. Furthermore, correlations between personal characteristics and attitudes toward homework were 
examined by a Pearson-correlation test.

\section{Results}

\subsection{Differences in the Attitudes of Teachers, Parents and the Public (University Students) Toward Homework}

To test the first research hypothesis, that differences exist between the attitudes of the various populations toward homework, statistical analysis was performed on the attitude means. The means relate to all the statements in the homework questionnaire, both positive and negative. Recoding of the positive statements was performed so that the scales of both negative and positive statements point in the same direction. The attitudes were scored on a scale of $1-5$ (where 1 represents strong disagreement and 5 represents strong agreement).

Table 1. Statistics of the differences between the general attitudes of the various populations toward homework

\begin{tabular}{ccccc}
\hline & Mean & SD & Min & Max \\
\hline $\begin{array}{c}\text { Teachers } \\
\mathrm{N}=50\end{array}$ & 3.50 & 0.63 & 1.85 & 4.77 \\
\hline $\begin{array}{c}\text { Parents } \\
\mathrm{N}=51\end{array}$ & 3.36 & 0.76 & 1.77 & 5 \\
\hline $\begin{array}{c}\text { University Students } \\
\mathrm{N}=50\end{array}$ & 3.13 & 0.83 & 1.54 & 4.38 \\
\hline
\end{tabular}

Table 1 shows that, in general, the attitudes of university students are the most negative $(M=3.13)$, next are those of the parents $(M=3.36)$, and teachers hold the most positive attitudes $(M=3.5)$. The standard deviation is low for all three populations (between 0.63 and 0.83 ).

To test the significance of the differences in the means of general attitudes toward homework between teachers, parents and university students, independent $\mathrm{t}$-tests were performed. It was found that the mean of teacher attitudes $(\mathrm{M}=3.5, \mathrm{SD}=0.63)$ is significantly higher than that of university students $(\mathrm{M}=3.13, \mathrm{SD}=0.83)$ $(\mathrm{t} 91.39=2.48, \mathrm{p}<.05)$. In contrast, it was found that the mean of teacher attitudes $(\mathrm{M}=3.5, \mathrm{SD}=0.63)$ is higher than that of parents $(\mathrm{M}=3.36, \mathrm{SD}=0.76)$, but not significantly ( $\mathrm{t} 99=1, \mathrm{p}>.05)$. In addition, it was found that the mean of parental attitudes $(\mathrm{M}=3.36, \mathrm{SD}=0.76)$ is not significantly higher than that of university students $(\mathrm{M}=3.13, \mathrm{SD}=0.83)(\mathrm{t} 99=1.43, \mathrm{p}>.05)$.

\subsection{Differences in Attitude Toward Reducing and Eliminating Homework}

To confirm the research hypotheses that parents hold a positive attitude toward changing the homework policy but differ on specific issues, and university students hold a positive attitude toward changing the homework policy, statistical analysis was performed on the responses to the relevant statements. The statements were scored on a scale of 1-5. The total number of subjects was 151 .

Table 2. Statistics of the differences in attitude toward changing the homework policy

\begin{tabular}{|c|c|c|c|}
\hline & $\begin{array}{c}\text { Teacher Average } \\
\begin{array}{c}\text { (SD) } \\
\mathrm{N}=50\end{array}\end{array}$ & $\begin{array}{c}\text { Parent Average } \\
\begin{array}{c}\text { (SD) } \\
\mathrm{N}=51\end{array}\end{array}$ & $\begin{array}{c}\text { University-Student } \\
\text { Average } \\
(\mathrm{SD}) \\
\mathrm{N}=50\end{array}$ \\
\hline $\begin{array}{l}\text { Reducing and eliminating homework is an } \\
\text { essential step. }\end{array}$ & $\begin{array}{c}2.14 \\
(1.01) \\
\end{array}$ & $\begin{array}{l}2.67 \\
(1.3) \\
\end{array}$ & $\begin{array}{c}3.3 \\
(1.19) \\
\end{array}$ \\
\hline $\begin{array}{l}\text { Finding alternatives to practice-and-drill } \\
\text { homework is essential. }\end{array}$ & $\begin{array}{c}3.38 \\
(1.27) \\
\end{array}$ & $\begin{array}{c}3.59 \\
(1.32)\end{array}$ & $\begin{array}{c}3.6 \\
(1.21) \\
\end{array}$ \\
\hline $\begin{array}{l}\text { Eliminating homework improves parent-child } \\
\text { relationships. }\end{array}$ & $\begin{array}{c}2.36 \\
(1.24) \\
\end{array}$ & $\begin{array}{c}2.84 \\
(1.37) \\
\end{array}$ & $\begin{array}{c}2.82 \\
(1.46)\end{array}$ \\
\hline $\begin{array}{l}\text { Eliminating homework improves teacher-student } \\
\text { relationships. }\end{array}$ & $\begin{array}{l}2.58 \\
(1.1) \\
\end{array}$ & $\begin{array}{c}2.75 \\
(1.45) \\
\end{array}$ & $\begin{array}{c}3.02 \\
(1.31) \\
\end{array}$ \\
\hline $\begin{array}{l}\text { General attitude toward creating a change (mean } \\
\text { of the four statement scores) }\end{array}$ & $\begin{array}{r}2.76 \\
(1.02) \\
\end{array}$ & $\begin{array}{c}3.12 \\
(1.22)\end{array}$ & $\begin{array}{r}3.45 \\
(1.01) \\
\end{array}$ \\
\hline
\end{tabular}

The results concerning parents and university students confirm the research hypotheses. The attitude of teachers 
toward creating a change was found to be the most negative.

Table 2 shows that parents hold a more positive attitude toward creating a change $(\mathrm{M}=3.12)$ than teachers $(\mathrm{M}=$ 2.76), while university students hold the most positive attitude $(M=3.45)$. Differences found between the statements in the questionnaire were as follows: parents and teachers support finding alternatives to practice-and-drill homework $(\mathrm{M}=3.59, \mathrm{M}=3.38)$ but oppose reducing and eliminating homework $(\mathrm{M}=2.67, \mathrm{M}$ $=2.14)$. University students, however, support both finding alternatives to practice-and-drill homework $(\mathrm{M}=$ 3.6) and reducing and eliminating homework $(\mathrm{M}=3.3)$.

Teachers, parents and university students all disagree with the statement that eliminating homework improves parent-child relationships $(\mathrm{M}=2.36, \mathrm{M}=2.84, \mathrm{M}=2.82$, respectively). However, university students believe to a slightly greater degree $(M=3.02)$ than teachers and parents $(M=2.58, M=2.75$, respectively $)$ that eliminating homework improves teacher-student relationships.

To test whether the differences in the attitudes of the various populations toward changing the homework policy are statistically significant, independent t-tests were performed. It was found that:

- There is no significant difference between the means of parents and teachers $(p>.05)$.

- There is no significant difference between the means of parents and university students $(p>.05)$.

- There is a significant difference between the means of teachers and university students $(p<.05)$.

The statistical-significance test proves that university students hold the most positive attitude toward changing the homework policy compared to teachers and parents, which further confirms the research hypothesis that the attitude of university students is in line with the Ministry of Education.

\subsection{The Relationship Between the Seniority and Age of Teachers and Their Attitude Toward Homework}

To determine whether there is a relationship between the general attitude of teachers toward homework and teaching seniority, a Pearson-correlation test was performed and no correlation between the variables was found $(p>.05)$. Another Pearson-correlation test showed no significant correlation between the age and attitude of teachers $(\mathrm{p}>.05)$. These results are not in line with the research hypotheses and the literature. It is possible that the results were affected by the limitations of the current study.

\subsection{Differences in Attitude Toward Homework Between Teachers of Various Grades}

To determine whether there are differences in attitude toward homework between teachers of various grades (1-6), statistical analysis was performed. The total number of subjects was 51. No noticeable differences were found between the means ( $\mathrm{M}=3.59, \mathrm{M}=3.47, \mathrm{M}=6.68, \mathrm{M}=3.23, \mathrm{M}=3.55, \mathrm{M}=3.36$, respectfully) and the standard deviation ranges over the interval $0.43-0.6$. All teachers were found to hold a positive attitude toward homework (as shown above) and no differences were found between teachers of various grades.

\subsection{Differences in Attitude Toward Homework Between Teachers from Different Disciplines (Sciences and Humanities)}

To determine whether there are differences in attitude toward homework between science $(M=3.7)$ and humanities $(M=3.33)$ teachers, independent $t$-tests were performed, and no significant difference was found $(\mathrm{T} 31=1.24, \mathrm{p}>.05)$. However, science teachers were found to hold a slightly more positive attitude.

\subsection{The Relationship Between Parental Background Variables (Child Birth-order Position, Number of Children in the Family, Age of Parents) and Attitude Toward Homework}

To determine whether the background variables of parents are related to their attitude toward homework as scored in the questionnaire, a Pearson-correlation test was performed. No correlation was found between the attitude of parents toward homework and the child's birth-order position $(p>.05)$, the number of children in the family $(\mathrm{p}>.05)$ or the age of the parents $(\mathrm{p}>.05)$.

\subsection{The Relationship Between the Degree of Homework Help Offered by Parents, as Scored in the Questionnaire, and Their Attitude Toward Homework}

Parents were asked to score the level of homework help they offer on a scale of 1-5 (where 1 represents no help and 5 represents a great degree of help). To determine whether a correlation exists between the attitudes of parents toward homework and the degree of help they offer as scored on the scale, a Pearson-correlation test was performed and no significant correlation was found $(\mathrm{p}>.05)$.

\section{Conclusion}

Homework and its aims have been extensively studied from various viewpoints. Because homework is a publicly 
discussed topic, the attitudes of influential populations of interest toward homework were examined here. The main issues examined were general attitudes toward conventional homework, the degree to which there is a desire to create change and whether practice and drill should continue to be performed at home or at school. The study results show that the populations examined (teachers, parents and university students) are generally supportive of homework, albeit with certain differences.

4.1 The First Research Hypothesis, That Teachers Hold a Positive Attitude Toward Homework, but There Are Differences Between Teachers with Different Levels of Seniority

This research hypothesis was partially confirmed. Teachers were found to be the most supportive of homework compared to the other populations examined, but no correlation was found between seniority and a positive or negative attitude.

When teachers were asked about practical changes to the homework policy, they opposed reducing or completely eliminating homework as recommended by the Ministry of Education, but supported creating alternatives to practice and drill. In a conversation with one of the teachers who participated in the research, he claimed that there is a need to adapt the homework assignments to the new generation. In his opinion, there is no need to eliminate or reduce homework, but there is a need to change it. He assigns his students (fifth-graders) their homework through Google Forms - electronic practice questions hosted by Google. In this way, students practice the school material on a computer, using a technology that is familiar to them, and receive immediate feedback.

In addition, no significant difference was found between science (math and English) teachers and humanities (Bible and history) teachers in their attitudes toward homework, but science teachers were found to hold a slightly more positive attitude. Previous studies show that practice and review are essential for success in subjects such as math and science (Cooper et al., 1989) and, moreover, the Ministry of Education claims that even if homework is reduced or eliminated in the distant future, no extreme changes will be made in the sciences.

4.2 The Second Research Hypothesis, That Most Parents Hold a Positive Attitude Toward Homework but Differ on Various Issues, Especially Those Concerning Practical Change

This hypothesis was confirmed. Most parents were found to support changing the current homework policy but oppose complete elimination. They believe that homework is essential, improves student achievements, helps create proper working habits and does not sabotage student-teacher or child-parent relationships. However, when asked about changing the conventional policy, parents responded positively. In a conversation with a parent of two elementary-school students, he claimed: "Homework is a burden for me no less than it is for the children." However, when asked explicitly whether homework should be completely eliminated, he responded negatively. No differences were found between background variables such as the number of children in a family, age of the parents and child birth-order position, and a positive or negative attitude of parents toward homework. It is possible that these variables do not directly affect parental attitude.

4.3 The Third Hypothesis, That the Public Opinion of Homework is in Line with the Ministry of Education and the Debate in the Media-Namely, to Reduce and Eliminate Homework

This hypothesis was confirmed. The general public (university students) was found to hold a neutral attitude toward homework, in contrast to the positive attitude held by teachers and parents, and to believe that eliminating homework may even improve child-parent relationships. In general, the public was found to support the changes recommended by the Ministry of Education. According to the research literature, the public attitude toward homework is mainly related to the prevailing social philosophy and to international economic trends rather than to studies on the efficacy of homework and its effectiveness in improving student achievements (Cooper et al., 1998; Cooper \& Valentine, 2001). It may be beneficial, in future research, to examine the relationship between economic aspects in Israel and the public attitude toward homework.

In a previous study that examined alternatives to homework, Fleischer and Ohel (1977) proved through an experiment that changing the homework does not necessarily cause lower student achievements or slow down the pace of study. An alternative to homework presented in the study was guided practice during school time. The achievements of the students who practiced in class were equal to those of the students who practiced at home.

According to the traditional definition, homework is "tasks that teachers assign to students at school, which the students are required to complete after school hours, and which are considered a common learning strategy" (Cooper, 1989). In the current research, it was found that the various populations that have an influence on the 
homework policy are mostly supportive of homework, but at the same time supportive of changing it. The research results are similar to those reached in previous studies, according to which teachers and parents are not yet ready to completely forgo homework and accept a change in the current policy (Davidovitch \& Yavich, 2017). Even approaching the third decade of the 21 st century, in an age of technological development that affects many areas of life - it seems that homework is still perceived as it always was - an indispensable part of the education system.

\section{Acknowledgments}

The authors wish to thank Hanna Del, undergraduate social-sciences student at Ariel University, for her assistance in the data collection for this study.

\section{References}

Burke, P. J., Christensen, J. C., Fessler, R., Mcdonnell, J. H., \& Price, J. R. (1987). The teacher career cycle: Model development and research report. Presented at the Annual Meeting of the American Educational Research Association, Washington, DC, April 20-24, 1987. Retrieved from https://files.eric.ed.gov/fulltext/ED289846.pdf

Buzukashvily, T. (2009). The role of parents in creating autonomous motivation for preparing homework: The importance of motivation and parental behavior (Master's thesis). Ben-Gurion University of the Negev, Beer-Sheva, Israel. (in Hebrew)

Cooper, H. (1989). Synthesis of research on homework. Educational Leadership, 47(3), 85-91.

Cooper, H., Lindsay, J. J., Nye, B., \& Greathouse, S. (1998). Relationships among attitudes about homework, amount of homework assigned and completed, and student achievement. Journal of Educational Psychology, 90(1), 70-83. https://doi.org/10.1037/0022-0663.90.1.70

Cooper, H., Steenbergen-Hu, S., \& Dent, A. L. (2012). Homework. In K. R. Harris, S. Graham, T. Urdan, A. G. Bus, S. Major, \& H. L. Swanson (Eds.), APA Educational Psychology Handbook, Vol. 3. Application to learning and teaching (pp. 475-495). Washington, DC: American Psychological Association. https://doi.org/10.1037/13275-019

Cooper, H., \& Valentine, J. C. (2001). Using research to answer practical questions about homework. Educational Psychologist, 36(3), 143-153. https://doi.org/10.1207/S15326985EP3603_1

Davidovitch, N., Yavich, R., \& Druckman, E. (2016). Don't throw out paper and pens yet: On the reading habits of students. Journal of International Education Research, 12(4), 129-144. https://doi.org/10.19030/jier.v12i4.9799

Davidovitch, N., \& Yavich, R. (2017). Views of students, parents, and teachers on homework in elementary school. International Education Studies, 10(10), 90-108. https://doi.org/10.5539/ies.v10n10p90

Davidovitch, N., \& Yavich, R. (2015). Technology-related involvement: The effect of the Mashov system on parent involvement in Israeli junior highs. Journal of International Education Research (JIER), 11(4), 243-252. https://doi.org/10.19030/jier.v11i4.9458

Dovrat, S., Abu-Saad, I., Otolangi, R., Buzaglo, M., Bar, I., Gibton, D., \& Kraus, M. (2006). The national program of education, Part A, Main recommendations. Jerusalem, Israel: The National Task Force for the Promotion of Education in Israel. (in Hebrew)

Eini, L. (2018, July 31). A change of policy in the Ministry of Education: Slowing down on homework. Ynet. Retrieved from https://www.ynet.co.il/

Fessler, R. (1995). Dynamics of teacher career stages. In T. R. Gusky, \& M. Huberman (Eds.), Professional development in education: New paradigms and practices (pp. 171-192). New York, NY: Teachers College Press.

Fleischer, G., \& Ohel, S. (1977). Homework in elementary school: Limitations and risks. Studies in Education, (17), 159-166. Retrieved from www.jstor.org/stable/23390513 (in Hebrew)

Haffila, M, Sarifa, A., \& Mohamed Mansoor, A. (2018). Teachers and students' attitudes towards homework a case study on Trichy urban primary schools. International Journal of English Research, 4(3), 1-4.

Henderson, M. (1996). Helping your student get the most out of homework [Brochure]. Chicago: National Parent-Teacher Association.

Katipoglu, R. S. (1993). The attitudes of parents and teachers toward homework (Master's thesis). Middle East 
Technical University, Ankara, Turkey. Retrieved from etd.lib.metu.edu.tr/upload/12616637/index.pdf

Kraus, S. J. (1995). Attitudes and the prediction of behavior: A meta-analysis of the empirical literature. Personality and Social Psychology Bulletin, 21(1), 58-75. https://doi.org/10.1177/0146167295211007

Maskit, D. (2006). Attitudes of teachers at various stages of their professional development toward creating changes in the teaching methods. Study and Research in Teacher Training, 10, 73-102. Retrieved from https://www.gordon.ac.il/sites/gordon/UserContent/files/d_maskit.pdf (in Hebrew)

Ministry of Education. (2006). Guidelines for year 5767/3(a), section 28-1.3: Homework in elementary schools. Jerusalem, Israel: Ministry of Education. Retrieved from cms.education.gov.il/EducationCMS/Applications/Mankal/EtsMedorim/3/3-1/HoraotKeva/

Rawson, K., Stahovich, T. F., \& Mayer, R. E. (2017). Homework and achievement: Using smartpen technology to find the connection. Journal of Educational Psychology, 109(2), 208-219. https://doi.org/10.1037/edu0000130

Rosário, P., Núñez, J. C., Vallejo, G., Cunha, J., Nunes, T., Mourão, R., \& Pinto, R. (2015). Does homework design matter? The role of homework's purpose in student mathematics achievement. Contemporary Educational Psychology, 43, 10-24. https://doi.org/10.1016/j.cedpsych.2015.08.001

Shemer, M. (1995). Learning style, homework-preparation style and creative thinking in teenagers (Master's thesis). Tel Aviv University, Tel Aviv, Israel. (in Hebrew)

Tam, V. C., \& Chan, R. M. (2009). Parental involvement in primary children's homework in Hong Kong. School Community Journal, 19(2), 81-100.

Trautwein, U., Niggli, A., Schnyder, I., \& Lüdtke, O. (2009). Between-teacher differences in homework assignments and the development of students' homework effort, homework emotions, and achievement. Journal of Educational Psychology, 101(1), 176-189. https://doi.org/10.1037/0022-0663.101.1.176

Xu, J., \& Yuan, R. (2003). Doing homework: Listening to students', parents', and teachers' voices in one urban middle school community. School Community Journal, 13(2), 25-44. Retrieved from https://www.researchgate.net/profile/Jianzhong_Xu3/publication/265324186_Doing_Homework_Listening _to_Students'_Parents'_and_Teachers'_Voices_in_One_Urban_Middle_School_Community/links/5576edd 208aeacff200040a1/Doing-Homework-Listening-to-Students-Parents-and-Teachers-Voices-in-One-UrbanMiddle-School-Community.pdf

\section{Copyrights}

Copyright for this article is retained by the author(s), with first publication rights granted to the journal.

This is an open-access article distributed under the terms and conditions of the Creative Commons Attribution license (http://creativecommons.org/licenses/by/4.0/). 